\title{
Pengaruh Iradiasi Sinar Gamma terhadap Pertumbuhan Protocorm Like Bodies Anggrek Dendrobium lasianthera (JJ. Smith) secara In Vitro
}

\author{
The Effects of Gamma Ray-Irradiation on The Growth of Protocorm Like Bodies \\ (PLBs) Dendrobium lasianthera (JJ . Smith) In Vitro
}

Fitro Adi Cahyo ${ }^{1}$ dan Diny Dinarti ${ }^{1 *}$

Diterima 19 Agustus 2015/Disetujui 09 November 2015

\begin{abstract}
The objective of this research was to determine the effects of gamma irradiation on protocorm like bodies (PLBS) Dendrobium lasianthera and Lethal dose (LD) 30 and 50 of gamma irradiation. The irradiation was conducted at the Center of Technology Application of Isotops and Radiation, Nuclear Energy Agency (PATIR-BATAN) and culture at Tissue Culture Laboratory of IPB from February 2014 to July 2014. The treatments were arranged in a completely randomized design (CRD) with a single factor of gamma irradiation doses, include i,g. $0 \mathrm{~Gy}, 20 \mathrm{~Gy}, 40 \mathrm{~Gy}, 60 \mathrm{~Gy}, 80$ Gy, and $100 \mathrm{~Gy}$. Each dose of gamma irradiation treatment was repeated 5 times. There were 30 experimental units. Each experimental unit consisted of five culture bottles containing 4 individually planted PLBS Dendrobium lasianthera. The results of this research showed that the increasing doses of gamma irradiation significantly decreased the percentage of alive PLBS, PLBs germination percentage, number of leaves, number of roots, the percentage of rooted PLBs. Morphological changes among other wider and spiral leaves were observed in the treated plantlets. Lethal dose $30 \%\left(L D_{30}\right)$ was at 19.7697 Gy and $L D_{50}$ was at $67.3504 \mathrm{~Gy}$.
\end{abstract}

Keywords: Dendrobium lasianthera, gamma irradiation, in vitro, Lethal dose (LD), mutation

\begin{abstract}
ABSTRAK
Penelitian ini bertujuan untuk mengetahui pengaruh iradiasi gamma terhadap pertumbuhan protocorm like bodies (PLBs) anggrek Dendrobium lasianthera serta menentukan Lethal dose (LD) 30 dan 50 dari iradiasi sinar gamma. Proses iradiasi dilakukan di Pusat Aplikasi Teknologi Isotop dan Radiasi, Badan Tenaga Nuklir Nasional (PATIR-BATAN) Proses kultur dilakukan di Laboratorium Kultur Jaringan IPB. Penelitian dilakukan dari bulan Februari 2014 hingga Juli 2014. Penelitian disusun menggunakan rancangan acak lengkap (RAL) dengan faktor tunggal yaitu dosis iradiasi gamma meliputi 0 Gy, 20 Gy, 40 Gy, 60 Gy, 80 Gy, dan $100 \mathrm{~Gy}$. Setiap dosis perlakuan iradiasi gamma diulang $5 \mathrm{kali}$, seluruhnya terdapat 30 satuan percobaan. Setiap satuan percobaan terdiri atas lima botol kultur yang masing-masing ditanam 4 PLBs anggrek Dendrobium lasianthera. Hasil penelitian ini menunjukkan bahwa peningkatan dosis iradiasi gamma nyata menurunkan persentase hidup PLBs, persentase PLBs berkecambah, jumlah daun, jumlah akar, dan persentase PLBs berakar. Perubahan planlet in vitro yang teramati antara lain daun melebar dan daun spiral. $L D_{30}$ berada pada 19.7697 Gy dan $L D_{50}$ pada $67.3504 \mathrm{~Gy}$.
\end{abstract}

Kata kunci: Dendrobium lasianthera, in vitro, iradiasi gamma, Lethal dose (LD), mutasi

\footnotetext{
${ }^{1}$ Departemen Agronomi dan Hortikultura, Fakultas Pertanian, Institut Pertanian Bogor (Bogor Agricultural University), Jl. Meranti Kampus Darmaga, Bogor 16680 Indonesia. Telp.\&Faks. 62-251-8629353. email: dinydinarti@ gmail.com. (*penulis korespondensi)
} 


\section{PENDAHULUAN}

Dendrobium merupakan genus anggrek yang terbanyak kedua di dunia. Genus anggrek ini tersebar di daratan Asia seperti Indonesia dan Filipina, serta Kepulauan Pasifik dan Australia. Di Kalimantan diperkirakan terdapat 143 spesies anggrek Dendrobium, dan sebagian besar ditemukan di hutan pada lokasi dengan ketinggian antara 600-1600 $\mathrm{m}$ di atas permukaan laut, hampir semuanya epifit, pertumbuhan simpodial dengan pseudo bulb yang berdaging, dan daun dengan berbagai bentuk (Sabran et al., 2003). Anggrek jenis Dendrobium merupakan komoditas yang paling digemari masyarakat karena sifatnya yang relatif lebih tahan lama dan memiliki warna bunga yang bervariasi, sehingga sangat berpotensi untuk dikembangkan untuk pasar dalam negeri maupun ekspor (Widiastoety et al., 2000).

Spesies anggrek Dendrobium terbaik banyak terdapat di kawasan timur Indonesia, seperti Papua dan Maluku (Widiastoety et al., 2010). Salah satu anggrek Dendrobium yang berasal dari Indonesia bagian timur adalah $D$. lasianthera. Anggrek jenis ini merupakan anggrek yang hidup di Papua dan Papua New Guinea. Ukuran bunga $D$. lasianthera cukup besar, tingginya bisa mencapai lebih dari 3 meter. Anggrek ini mempunyai bunga yang indah, pada satu tandan bunga bisa muncul antara 10-30 kuntum bunga (Smart, 2008; Alamendah, 2012). Habitus tanaman yang terlalu tinggi dan beratnya tandan bunga yang memiliki begitu banyak kuntum bunga akan membuat tanaman mudah rebah saat terkena angin kencang dan mengakibatkan bunga menjadi rusak. Selain itu akibat ukuran bunga yang terlalu besar akan memerlukan tempat yang lebih besar. Oleh sebab itu, perbaikan sifat genetik tanaman dirasa perlu untuk mendapatkan morfologi tanaman yang lebih baik.

Menurut Soedjono (2003) perbaikan sifat agronomi dan genetik dapat dilakukan secara konvensional, yakni dengan persilangan antar spesies, varietas, genera, atau kerabat yang memiliki sifat yang diinginkan. Metode pemuliaan tanaman konvensional memiliki keterbatasan, antara lain memerlukan waktu yang cukup lama, sulit memilih dengan tepat gen-gen yang menjadi target seleksi untuk diekspresikan pada sifat-sifat morfologi atau agronomi, rendahnya frekuensi individu hasil pemuliaan yang berada dalam suatu populasi yang besar sehingga menyulitkan kegiatan seleksi untuk mendapatkan hasil yang valid secara statistik, dan pautan gen antara sifat yang diinginkan sulit dipisahkan saat melakukan persilangan (Lamaji et al., 1999). Menurut Widiastoety (2009) tanaman anggrek memiliki pertumbuhan vegetatif yang sangat lambat sehingga diperlukan metode khusus dalam teknologi pembibitan untuk memacu pertumbuhannya.

Cara lain untuk menginduksi keragaman genetik selain dengan persilangan adalah dengan pemberian mutagen, baik mutagen fisik (sinar $X$, sinar $\alpha$, sinar $\beta$, sinar $\gamma$ ) ataupun mutagen kimia (EMS, NMU, NTG) (Poespodarsono, 1998). Mutasi adalah perubahan pada materi genetik suatu makhluk yang terjadi secara tiba-tiba dan acak serta merupakan dasar bagi sumber variasi organisme hidup yang bersifat terwariskan (Suranto, 2003). Penelitian yang dilakukan oleh Soedjono et al. (1996) menunjukkan adanya perubahan warna pada Dendrobium ekapolpanda hasil iradiasi gamma semakin tinggi dosis iradiasi dimulai dari dosis 50 Gy maka warna PLBs akan semakin pucat akibat adanya kerusakan pada sel. Perlakuan iradiasi pada PLBs yang diterapkan pada penelitian ini adalah 0, 20, 40, 60, 80, dan 100 Gy. Penelitian ini bertujuan mengetahui pengaruh iradiasi gamma terhadap pertumbuhan PLBs, serta mendapatkan Lethal Dose $(L D) 30$ dan 50 dari proses iradiasi gamma pada anggrek $D$. lasianthera.

\section{BAHAN DAN METODE}

Penelitian dilakukan di Laboratorium Kultur Jaringan Departemen Agronomi dan Hortikultura Fakultas Pertanian Institut Pertanian Bogor. Perlakuan iradiasi dilakukan dengan Gamma Chamber di Pusat Aplikasi Teknologi Isotop dan Radiasi, Badan Tenaga Nuklir Nasional (PATIR-BATAN). Penelitian ini dilaksanakan pada bulan Februari 2014 hingga Juli 2014.

Bahan yang digunakan dalam penelitian ini adalah PLBs anggrek $D$. lasianthera. Media yang digunakan pada penelitian ini adalah media dasar Vacin and Went (VW) yang ditambahkan dengan ekstrak tomat, pisang ambon, dan arang aktif. Alat-alat yang 
digunakan dalam penelitian ini adalalah alatalat standar laboratorium kultur jaringan.

Pembuatan media (VW) dilakukan dengan mencampurkan bahan-bahan sebagai berikut: $\mathrm{Ca}_{3}\left(\mathrm{PO}_{4}\right)_{2}, \quad \mathrm{KNO}_{3}, \quad \mathrm{KH}_{2} \mathrm{PO}_{4}, \quad \mathrm{MgSO}_{4} 7 \mathrm{H}_{2} \mathrm{O}$, $\left(\mathrm{NH}_{4}\right)_{2} \mathrm{SO}_{4}, \quad \mathrm{MnSO}_{4}, \quad 2 \mathrm{H}_{2} \mathrm{O}, \quad \mathrm{Fe}\left(\mathrm{C}_{4} \mathrm{H}_{4} \mathrm{O}_{6}\right)_{3}$. Larutan stok di buat untuk masing-masing bahan yang akan digunakan dengan pemekatan 50 kali. Media dibuat dengan memipet larutan stok sesuai dengan konsentrasi yang ditetapkan. Semua bahan dilarutkan dengan aquades kemudian ditambahkan gula $20 \mathrm{~g} \mathrm{~L}^{-1}$, ekstrak tomat $30 \mathrm{ml} \mathrm{L}^{-1}$, pisang ambon $30 \mathrm{~g} \mathrm{~L}^{-1}$, setelah semuanya tercampur kemudian ditambahkan aquades sampai batas tera. Derajat keasaman $(\mathrm{pH})$ media diatur hingga mencapai 5.8-6 dengan penambahan $\mathrm{HCl}$ jika $\mathrm{pH}$ terlalu tinggi dan penambahan $\mathrm{KOH}$ jika $\mathrm{pH}$ terlalu rendah. Arang aktif $2 \mathrm{~g} \mathrm{~L}^{-1}$ dan agar-agar $8 \mathrm{~g} \mathrm{~L} \mathrm{~L}^{-1}$ ditambahkan ke dalam larutan media dan dipanaskan sambil diaduk. Setelah media mendidih kemudian dibagi sesuai dengan banyaknya botol percobaan. Botol yang telah berisi media disterilkan dengan autoclave pada suhu $121{ }^{\circ} \mathrm{C}$ selama 20 menit. Media diinkubasi di dalam ruang kultur selama 1 minggu sebelum ditanami untuk melihat berapa banyak media yang mengalami kontaminasi.

PLBs D. lasianthera ditanam pada media VW yang telah disiapkan dan dibagi sesuai dengan banyaknya dosis iradiasi yang akan diaplikasikan. Selanjutnya botol kultur yang berisi PLBs diiradiasi di BATAN sesuai dengan dosis perlakuan yang telah dirancang. PLBs yang telah diirradiasi kemudian dipindahkan ke media baru dengan komposisi media yang sama dan ditanam 4 PLBs untuk setiap botol. Subkultur dilakukan setiap 3 bulan menggunakan media yang sama.

Pengamatan dilakukan setiap minggu dimulai 1 minggu setelah tanam (MST) hingga kultur berumur 22 MST. Peubah yang diamati ialah persentase hidup PLBs, jumlah daun yang terbentuk, jumlah akar, persen jumlah PLBs yang berkecambah, dan persen PLBs berakar. Semua peubah tersebut diukur setiap minggu. Peubah bentuk daun, dan morfologi akar (ukuran besar, sedang, kecil) diukur pada akhir pengamatan.

Rancangan lingkungan yang digunakan pada percobaan ini adalah rancangan acak lengkap (RAL) dengan faktor tunggal yaitu dosis iradiasi sinar gamma. Terdapat 6 taraf dosis iradiasi sinar gamma yaitu 0, 20, 40, 60, 80, dan 100 Gy. Setiap dosis perlakuan iradiasi gamma diulang 5 kali. Seluruhnya terdapat 30 satuan percobaan dan setiap satuan percobaan terdiri 5 botol kultur yang masing-masing ditanam 4 PLBs anggrek $D$. lasianthera.

Model statistik yang digunakan sebagai berikut :

$$
\mathrm{Yij}=\mu+\tau_{\mathrm{i}}+\varepsilon_{\mathrm{ij}}
$$

Yij : Respon pengamatan pada perlakuan iradiasi gamma ke-i, dan ulangan ke-j

$\mu \quad$ : Nilai tengah umum

$\tau_{\mathrm{i}} \quad$ : pengaruh iradiasi gamma ke-i

$\varepsilon_{\mathrm{ij}} \quad$ : pengaruh galat percobaan perlakuan iradiasi gamma ke-i dan ulangan ke-j

Hasil pengamatan dianalisis menggunakan analisis ragam (uji F) pada selang kepercayaan 95\% $(\alpha=5 \%)$. Apabila terdapat pengaruh nyata, maka dilakukan uji lanjut dengan Duncan Multiple Range Test (DMRT), serta dilakukan analisis $L D_{30}$ dan $L D_{50}$. Cara menentukan $L D_{50}$ dan $L D_{30}$ menggunakan persamaan garis menurut Harmita dan Radji (2008).

$$
\mathbf{Y}=\mathbf{a}+\mathbf{b} \mathbf{x}
$$

$\mathrm{Y}=\%$ kematian

$\mathrm{X}=\log$ dosis

\section{HASIL DAN PEMBAHASAN}

Hasil penelitian yang telah dilakukan selama 6 bulan menunjukkan bahwa dosis iradiasi nyata mempengaruhi semua peubah yang diamati yaitu persentase PLBs hidup, persentase PLBs berkecambah, jumlah daun, jumlah akar, dan persentase PLBs berakar.

Perbedaan nyata pada setiap peubah yang diamati terlihat hampir pada setiap minggu pengamatan mulai dari minggu ke-6 kecuali pada peubah persentase hidup yang baru terlihat perbedaanya pada minggu ke-9. PLBs yang diiradiasi dengan dosis tinggi terutama pada dosis 80 Gy dan 100 Gy mulai mengalami kematian pada minggu ke-9 hingga minggu ke-22.

Keadaan tersebut menunjukkan bahwa dosis iradiasi yang diberikan mengakibatkan kerusakan sel yang cukup besar dan PLBs yang tidak mampu memulihkan diri hanya akan bertahan kurang lebih selama 9 minggu saja setelah itu akan mengalami kematian, 
sesuai dengan pernyataan Romeida et al. (2013) bahwa peningkatan dosis paparan yang lebih tinggi mengakibatkan PLBs hanya mampu bertahan hidup selama 2 bulan saja.

\section{Persentase Hidup PLBs}

Peningkatan dosis radiasi nyata menurunkan persentase hidup PLBs anggrek D. lasianthera, mulai dari 9 MST hingga 22 MST. Pada minggu pertama hingga minggu ke-6 sebagian besar PLBs masih dapat bertahan dari kerusakan sel yang diakibatkan oleh iradiasi gamma yang diterima, setelah masuk minggu ke-9 hingga ke-22 PLBs anggrek mengalami penurunan daya hidup terutama pada iradiasi 80 Gy dan 100 Gy (Tabel 1).

Kematian PLBs terbesar yang diakibatkan oleh iradiasi terjadi pada perlakuan dosis 80 dan 100 Gy. Pada minggu ke-15 PLBs dengan iradiasi 80 Gy mengalami kematian 50\%, dan pada minggu ke-22 PLBs anggrek yang hidup hanya tinggal $35 \%$. PLBs dengan iradiasi 100 Gy mengalami kematian lebih dari 50\% pada minggu ke-15 dan minggu ke-22 hanya tinggal 19\%. Keadaan tersebut terjadi karena semakin tinggi dosis iradiasi yang diberikan kepada PLBs maka kerusakan sel akan semakin besar sehingga PLBs tidak mampu melakukan pemulihan dan akhirnya mati. Penelitian yang dilakukan oleh Kurniati (2004) menyebutkan bahwa PLBs anggrek Phalaenopsis himatsuri $x$ Doritaenopsis Modern Beauty yang diberikan perlakuan dosis iradiasi gamma 40 Gy hanya dapat bertahan hidup 10-20\%. Dosis iradiasi 40 Gy menyebabkan sebagian besar planlet tersebut mengalami kelambatan pertumbuhan, berwarna cokelat dan akhirnya mati.

Kematian PLBs yang disebabkan iradiasi ditunjukkan dengan perubahan warna PLBs dari hijau menjadi kekuningan selanjutnya menjadi kecokelatan dan akhirnya menghitam dan mati. Keadaan tersebut serupa dengan penelitian yang dilakukan oleh Romeida et al. (2013) yang menjelaskan bahwa gejala kematian PLBs anggrek Spatoglotis plicata Blum hasil iradiasi dimulai dengan menguningnya PLBs, selanjutnya PLBs menjadi cokelat dan menghitam. Massa PLBs terlihat berwarna hitam tanda terjadi kematian sel akibat paparan sinar gamma. Kejadian tersebut terjadi pada semua PLBs hasil iradiasi yang tidak mampu melakukan pemulihan kembali pada kerusakan sel yang dialami. PLBs yang mampu melakukan pemulihan dan berhasil bertahan hidup maka memungkinkan untuk menjadi tanaman mutan.

\section{Persentase PLBs Berkecambah}

Peningkatan dosis radiasi menurunkan persentase PLBs yang berkecambah (Tabel 2). Persentase PLBs berkecambah didapatkan dari perbandingan antara jumlah total PLBs yang berkecambah dengan jumlah total PLBs yang ditanam. PLBs yang terkena iradiasi dengan dosis tinggi terutama pada dosis 80 dan 100 Gy memiliki laju pertumbuhan yang jauh lebih lambat dibandingkan dengan yang lain (Tabel 2). Royani et al. (2012) menyebutkan bahwa pertumbuhan tanaman sambiloto dengan perlakuan iradiasi termasuk lambat, hal tersebut diakibatkan karena adanya efek iradiasi yang menyebabkan pertumbuhan tanaman tersebut menjadi lambat.

Kriteria PLBs yang berkecambah dilihat dari PLBs yang telah mengalami penonjolan dan kemudian merekah pada ujung PLBs anggrek dimana setelah proses tersebut selanjutnya akan mucul bakal daun pada hasil rekahan yang telah terbentuk. Siska et al. (2013) melaporkan bahwa munculnya tunas ditandai dengan membengkaknya PLBs yang kemudian diikuti dengan merekahnya ujung eksplan sehingga membentuk nod (bakal tunas). Calon tunas mikro dapat terbentuk pada rekahan tersebut yang ditandai dengan munculnya ujung helai daun.

Tabel 1. Persentase hidup PLBs anggrek $D$. lasianthera pada berbagai dosis iradiasi gamma

\begin{tabular}{ccccccc}
\hline \multirow{2}{*}{$\begin{array}{c}\text { Dosis } \\
(\text { Gy })\end{array}$} & 6 & 9 & 12 & 15 & 18 & 22 \\
\cline { 2 - 7 } & \multicolumn{6}{c}{ Umur Planlet (MST) } \\
\hline 0 & 75 & $77 \mathrm{a}$ & $75 \mathrm{a}$ & $73 \mathrm{a}$ & $74 \mathrm{a}$ & $76 \mathrm{a}$ \\
20 & 65 & $66 \mathrm{~b}$ & $67 \mathrm{ab}$ & $68 \mathrm{ab}$ & $64 \mathrm{ab}$ & $64 \mathrm{ab}$ \\
40 & 64 & $68 \mathrm{ab}$ & $64 \mathrm{bc}$ & $68 \mathrm{ab}$ & $63 \mathrm{ab}$ & $63 \mathrm{ab}$ \\
60 & 72 & $64 \mathrm{bc}$ & $63 \mathrm{bc}$ & $60 \mathrm{~b}$ & $59 \mathrm{~b}$ & $58 \mathrm{~b}$ \\
80 & 67 & $57 \mathrm{c}$ & $50 \mathrm{~d}$ & $50 \mathrm{~cd}$ & $35 \mathrm{c}$ & $35 \mathrm{c}$ \\
100 & 77 & $64 \mathrm{bc}$ & $56 \mathrm{~cd}$ & $43 \mathrm{~d}$ & $25 \mathrm{c}$ & $19 \mathrm{~d}$ \\
\hline
\end{tabular}

Keterangan: Angka pada kolom yang sama yang diikuti huruf yang sama menunjukkan hasil yang tidak berbeda nyata berdasarkan DMRT pada taraf $\alpha=5 \%$. 
Tabel 2. Persentase berkecambah PLBs anggrek $D$. lasianthera pada berbagai dosis iradiasi gamma

\begin{tabular}{|c|c|c|c|c|c|c|}
\hline \multirow{2}{*}{$\begin{array}{l}\text { Dosis } \\
\text { (Gy) }\end{array}$} & \multicolumn{6}{|c|}{ Umur Planlet (MST) } \\
\hline & 6 & 9 & 12 & 15 & 18 & 22 \\
\hline & \multicolumn{6}{|c|}{.. PLBs Berkecambah $(\%) \ldots$} \\
\hline 0 & $72 a$ & $77 \mathrm{a}$ & $75 a$ & $73 a$ & $74 a$ & $76 a$ \\
\hline 20 & $56 b$ & $62 b$ & $67 b$ & $68 \mathrm{a}$ & $64 \mathrm{ab}$ & $64 a b$ \\
\hline 40 & $56 b$ & $59 \mathrm{bc}$ & $64 \mathrm{~b}$ & $66 \mathrm{a}$ & $63 \mathrm{ab}$ & $63 \mathrm{ab}$ \\
\hline 60 & $56 b$ & $57 \mathrm{bc}$ & $62 b$ & $60 \mathrm{ab}$ & $59 b$ & $58 b$ \\
\hline 80 & $51 b$ & $49 c$ & $49 \mathrm{c}$ & $48 b$ & $35 \mathrm{c}$ & $35 c$ \\
\hline 100 & $50 \mathrm{~b}$ & $48 \mathrm{c}$ & $48 \mathrm{c}$ & $31 \mathrm{c}$ & $25 \mathrm{c}$ & $19 \mathrm{~d}$ \\
\hline
\end{tabular}

Sampai minggu ke-6 tidak ada perbedaan nyata pada setiap dosis iradiasi yang diaplikasikan mulai dari dosis 20 hingga 100 Gy. Pada perlakuan dosis iradiasi 80 dan 100 Gy persentase PLBs berkecambah terus mengalami penurunan setelah minggu ke-6 sampai minggu ke-22. Menurut Romeida et al. (2013) bila PLBs hasil iradiasi gamma mengalami kerusakan sel yang sangat besar maka PLBs tidak akan mampu melakukan pemulihan dan bertahan hidup, sementara sel-sel yang mampu memulihkan diri akan membelah dan membentuk PLBs baru dan berkembang menjadi tanaman mutan.

\section{Jumlah Daun}

Perlakuan dosis iradiasi yang diberikan sangat nyata menekan jumlah daun yang terbentuk pada planlet anggrek. Semakin tinggi dosis yang diberikan maka kemampuan planlet anggrek untuk membentuk daun semakin rendah. Pada minggu ke-12 hingga minggu ke-22, planlet anggrek yang diberi dosis iradiasi lebih tinggi akan memiliki ratarata jumlah daun lebih rendah dibandingkan dengan PLBs tanpa iradiasi (Tabel 3).

Jumlah daun pada perlakuan dosis iradiasi 80 Gy tidak berbeda nyata dengan perlakuan dosis iradiasi 100 Gy. Kedua perlakuan tersebut memiliki jumlah daun yang sangat sedikit dengan laju pertambahan daun yang lambat. Keadaan tersebut disebabkan karena selain banyaknya PLBs anggrek yang tidak mampu bertahan hidup juga karena PLBs yang mampu bertahan hidup pada dosis iradiasi ini sebagian hanya mampu tumbuh hingga fase perkecambahan saja setelah itu pertumbuhan akan terhenti. Penelitian yang dilakukan oleh Devy dan Sastra (2006) menunjukkan bahwa kultur jahe hasil iradiasi gamma yang telah bertunas tidak semuanya dapat membentuk daun. Kurniati (2004) menyebutkan bahwa dosis iradiasi 40 Gy yang diaplikasikan pada anggrek Phal. Hinamatsuri $x$ Doritaenopsis modern beauty. Modern Beauty menyebabkan sel yang terkena iradiasi mengalami kematian, sehingga terjadi hambatan pembentukan organ planlet, termasuk daun.

Rata-rata jumlah daun perplanlet memiliki perbedaan yang nyata pada beberapa taraf dosis iradiasi (Tabel 4). Pada minggu ke6 seluruh perlakuan dosis iradiasi tidak menunjukkan perbedaan yang nyata kecuali pada dosis iradiasi 0 Gy. Pada minggu selanjutnya dosis iradiasi 20,40 , dan 60 Gy mulai menunjukkan perbedaan nyata pada minggu ke- 9, 12 dan 15. Ketiga dosis tersebut mulai menunjukkan pertumbuhan daun yang lebih cepat dibandingkan dengan dosis iradiasi 80 dan 100 Gy sehingga jumlah daun yang dihasilkan menjadi lebih banyak. Keadaan tersebut menunjukkan bahwa dosis iradiasi tinggi yang diaplikasikan kepada PLBs anggrek $D$. lasianthera menyebabkan rusaknya sel tanaman sehingga mengakibatkan terhambatnya pertumbuhan daun.

\section{Jumlah Akar}

Hasil analisis uji ragam menunjukkan bahwa persen PLBs berakar menunjukkan respon yang nyata terhadap perlakuan dosis iradiasi. Semakin tinggi dosis iradiasi yang diberikan maka kemampuan setiap planlet untuk membentuk akar juga akan semakin kecil. Keadaan tersebut terlihat pada minggu ke-9 hingga minggu ke-22 (Tabel 5).

Tabel 3. Rata-rata jumlah daun planlet anggrek D. lasianthera pada berbagai dosis iradiasi gamma

\begin{tabular}{|c|c|c|c|c|c|c|}
\hline \multirow{2}{*}{$\begin{array}{l}\begin{array}{l}\text { Dosis } \\
\text { (Gy) }\end{array} \\
\end{array}$} & \multicolumn{6}{|c|}{ Umur Planlet (MST) } \\
\hline & 6 & 9 & 12 & 15 & 18 & 22 \\
\hline & \multicolumn{6}{|c|}{......Jumlah Daun (Helai).... } \\
\hline 0 & $4.6 \mathrm{a}$ & $16.2 \mathrm{a}$ & $28.4 \mathrm{a}$ & $35.6 \mathrm{a}$ & $41.0 \mathrm{a}$ & $62.0 \mathrm{a}$ \\
\hline 20 & $1.2 \mathrm{~b}$ & $9.4 \mathrm{~b}$ & $13.2 \mathrm{~b}$ & $22.2 \mathrm{~b}$ & $30.6 \mathrm{~b}$ & $36.4 \mathrm{~b}$ \\
\hline 40 & $1.0 \mathrm{~b}$ & $2.6 \mathrm{c}$ & $8.6 \mathrm{c}$ & $14.2 \mathrm{c}$ & $22.8 b c$ & $33.4 \mathrm{bc}$ \\
\hline 60 & $0.6 \mathrm{~b}$ & $1.0 \mathrm{c}$ & $2.6 \mathrm{~d}$ & $9.0 \mathrm{~cd}$ & $18.0 \mathrm{c}$ & $26.4 \mathrm{c}$ \\
\hline 80 & $0.2 b$ & $0.8 \mathrm{c}$ & $0.8 \mathrm{~d}$ & $2.2 \mathrm{~d}$ & $4.2 \mathrm{~d}$ & $7.2 \mathrm{~d}$ \\
\hline 100 & $1.0 \mathrm{~b}$ & $1.2 \mathrm{~d}$ & $1.0 \mathrm{~d}$ & $2.2 \mathrm{~d}$ & $3.4 \mathrm{~d}$ & $6.0 \mathrm{~d}$ \\
\hline \multicolumn{2}{|c|}{ Keterangan: } & $\begin{array}{l}\text { Angka } \\
\text { diikuti } \\
\text { hasil } \\
\text { berdasa }\end{array}$ & $\begin{array}{l}\text { pada } \\
\text { huruf } \\
\text { yang } \\
\text { arkan D }\end{array}$ & $\begin{array}{l}\text { kolom } \\
\text { yang } s\end{array}$ & yang & ma ya \\
\hline
\end{tabular}


Tabel 4. Rata-rata jumlah daun perplanlet anggrek D. lasianthera pada berbagai dosis iradiasi gamma

\begin{tabular}{ccccccc}
\hline \multirow{2}{*}{$\begin{array}{c}\text { Dosis } \\
\text { (Gy) }\end{array}$} & 6 & 9 & 12 & 15 & 18 & 22 \\
\cline { 2 - 7 } & $\ldots \ldots \ldots \ldots \ldots . J u m l a h$ & Daun (Helai) ............. \\
0 & $0.3 \mathrm{a}$ & $1.1 \mathrm{a}$ & $1.9 \mathrm{a}$ & $2.4 \mathrm{a}$ & $2.8 \mathrm{a}$ & $4.1 \mathrm{a}$ \\
20 & $0.1 \mathrm{~b}$ & $0.1 \mathrm{~b}$ & $1.5 \mathrm{~b}$ & $1.6 \mathrm{~b}$ & $2.4 \mathrm{ab}$ & $2.8 \mathrm{~b}$ \\
40 & $0.1 \mathrm{~b}$ & $0.2 \mathrm{c}$ & $0.8 \mathrm{c}$ & $1.0 \mathrm{c}$ & $1.8 \mathrm{bc}$ & $2.7 \mathrm{~b}$ \\
60 & $0.0 \mathrm{~b}$ & $0.1 \mathrm{c}$ & $0.3 \mathrm{~d}$ & $0.7 \mathrm{~cd}$ & $1.5 \mathrm{bcd}$ & $2.2 \mathrm{~b}$ \\
80 & $0.0 \mathrm{~b}$ & $0.1 \mathrm{c}$ & $0.1 \mathrm{~d}$ & $0.2 \mathrm{~d}$ & $0.6 \mathrm{~d}$ & $1.1 \mathrm{c}$ \\
100 & $0.1 \mathrm{~b}$ & $0.1 \mathrm{c}$ & $0.1 \mathrm{~d}$ & $0.4 \mathrm{~d}$ & $1.1 \mathrm{~cd}$ & $2.0 \mathrm{bc}$
\end{tabular}

Keterangan: Angka pada kolom yang sama yang diikuti huruf yang sama menunjukkan hasil yang tidak berbeda nyata berdasarkan DMRT pada taraf $\alpha=5 \%$.

Perlakuan dosis iradiasi 20 Gy yang diaplikasikan pada planlet menghasilkan ratarata persentase jumlah planlet berakar yang cukup tinggi dibandingkan dengan perlakuan iradiasi lain selain kontrol. Keadaan tersebut diakibatkan karena kerusakan yang disebabkan oleh dosis iradiasi 20 Gy tidak begitu besar sehingga sebagian besar planlet masih mampu memulihkan diri dengan lebih cepat dan akhirnya mampu tumbuh secara normal. Sementara itu pada perlakuan dosis iradiasi 40 Gy dan 60 Gy memiliki rata-rata persentase planlet berakar lebih rendah dibandingkan dengan dosis iradiasi 20 Gy. Perlakuan dosis iradiasi 80 dan 100 Gy memiliki rata-rata persentase planlet berakar paling rendah. Terbentuknya akar pada perlakuan dosis tersebut baru terlihat pada minggu ke-12 dengan rata-rata $1 \%$. Hingga pada minggu ke22, perlakuan dosis iradiasi 80 Gy hanya menghasilkan rata-rata sebesar $11 \%$ dan pada perlakuan dosis iradiasi 100 Gy nilai rata-rata yang dihasilkan sebesar 6\%. Menurut Aziz et al. (2014) bahwa kombinasi media dan zat pengatur tumbuh optimal dapat meningkatkan persentase multiplikasi dan kalus, serta jumlah akar dan daun pada PLBs anggrek silangan.

Hasil analisis ragam menunjukkan bahwa perlakuan dosis iradiasi nyata menekan pertumbuhan akar. Semakin tinggi dosis iradiasi yang diberikan maka jumlah akar yang dihasilkan akan semakin sedikit (Tabel 6). Menurut Gonzales (2007) bahwa dosis iradiasi yang diberikan pada tiga spesies anggrek tanah menyebabkan penurunan terhadap jumlah akar mulai dari dosis 10 Gy dan pertumbuhan semakin terhambat pada dosis yang lebih tinggi.
Tabel 5. Persentase planlet berakar pada anggrek $D$. lasianthera pada berbagai dosis iradiasi gamma

\begin{tabular}{|c|c|c|c|c|c|c|}
\hline \multirow{2}{*}{$\begin{array}{c}\text { Dosis } \\
\text { (Gy) }\end{array}$} & \multicolumn{6}{|c|}{ Umur Planlet (MST) } \\
\hline & 6 & 9 & 12 & 15 & 18 & 22 \\
\hline \multicolumn{7}{|c|}{...Planlet Berakar (\%). } \\
\hline 0 & $6 a$ & $21 \mathrm{a}$ & $54 \mathrm{a}$ & $56 a$ & $69 a$ & $76 a$ \\
\hline 20 & $0 \mathrm{~b}$ & $5 b$ & $37 b$ & $55 \mathrm{a}$ & $58 \mathrm{a}$ & $64 \mathrm{~b}$ \\
\hline 40 & $0 \mathrm{~b}$ & $2 b c$ & $11 \mathrm{c}$ & $23 b$ & $40 \mathrm{~b}$ & $51 \mathrm{c}$ \\
\hline 60 & $0 b$ & $2 b c$ & $10 \mathrm{c}$ & $16 \mathrm{bc}$ & $31 b$ & $39 d$ \\
\hline 80 & $0 \mathrm{~b}$ & $0 \mathrm{c}$ & $1 \mathrm{c}$ & $6 \mathrm{~cd}$ & $8 \mathrm{c}$ & $11 \mathrm{e}$ \\
\hline 100 & $0 \mathrm{~b}$ & $0 \mathrm{c}$ & $1 \mathrm{c}$ & $3 \mathrm{~d}$ & $4 \mathrm{c}$ & $6 e$ \\
\hline & \multicolumn{6}{|c|}{$\begin{array}{l}\text { Angka pada kolom yang sama yang } \\
\text { diikuti huruf yang sama menunjukkan } \\
\text { hasil yang tidak berbeda nyata } \\
\text { berdasarkan DMRT pada taraf } \alpha=5 \% \text {. }\end{array}$} \\
\hline
\end{tabular}

Tabel 6. Rata-rata jumlah akar planlet anggrek D. lasianthera pada berbagai dosis iradiasi gamma

\begin{tabular}{ccccccc}
\hline \multirow{2}{*}{$\begin{array}{c}\text { Dosis } \\
(\mathrm{Gy})\end{array}$} & \multicolumn{6}{c}{ Umur Planlet (MST) } \\
\cline { 2 - 7 } & 6 & 9 & 12 & 15 & 18 & 22 \\
\hline \multicolumn{6}{c}{$\ldots \ldots \ldots \ldots$. Jumlah Akar........... } \\
0 & $1.2 \mathrm{a}$ & $5.4 \mathrm{a}$ & $18.6 \mathrm{a}$ & $29.4 \mathrm{a}$ & $38.6 \mathrm{a}$ & $67.2 \mathrm{a}$ \\
20 & $0.0 \mathrm{~b}$ & $1.0 \mathrm{~b}$ & $13.8 \mathrm{~b}$ & $25.8 \mathrm{a}$ & $37.0 \mathrm{a}$ & $56.8 \mathrm{ab}$ \\
40 & $0.0 \mathrm{~b}$ & $0.4 \mathrm{bc}$ & $4.0 \mathrm{~cd}$ & $11.8 \mathrm{~b}$ & $21.6 \mathrm{~b}$ & $54.2 \mathrm{ab}$ \\
60 & $0.0 \mathrm{~b}$ & $0.4 \mathrm{bc}$ & $4.8 \mathrm{c}$ & $10.6 \mathrm{~b}$ & $21.2 \mathrm{~b}$ & $43.2 \mathrm{~b}$ \\
80 & $0.0 \mathrm{~b}$ & $0.0 \mathrm{c}$ & $0.2 \mathrm{~d}$ & $1.2 \mathrm{c}$ & $3.0 \mathrm{c}$ & $7.8 \mathrm{c}$ \\
100 & $0.0 \mathrm{~b}$ & $0.0 \mathrm{c}$ & $0.2 \mathrm{~d}$ & $1.2 \mathrm{c}$ & $3.0 \mathrm{c}$ & $6.2 \mathrm{c}$ \\
\hline
\end{tabular}

Keterangan: Angka pada kolom yang sama yang diikuti huruf yang sama menunjukkan hasil yang tidak berbeda nyata berdasarkan DMRT pada taraf $\alpha=5 \%$.

Kerusakan sel yang diakibatkan oleh iradiasi yang diberikan berpengaruh terhadap pertumbuhan akar. Semakin tinggi dosis yang diberikan semakin sedikit jumlah akar yang dihasilkan oleh tanaman akibat kerusakan sel tanaman yang semakin besar. Menurut Kurniati (2004) bahwa dosis iradiasi 10 Gy dan 20 Gy adalah dosis yang masih sesuai untuk pertumbuhan akar dan pertumbuhan daun pada anggrek Palaenopsis. Pada minggu ke-6 belum terlihat adanya pembentukan akar pada semua dosis iradiasi yang diaplikasikan kecuali pada dosis $0 \mathrm{~Gy}$, pertumbuhan akar pada dosis iradiasi 20, 40 dan 60 Gy baru terjadi pada minggu ke-9. Pada perlakuan dosis iradiasi 20 hingga 60 Gy masih memiliki rata-rata jumlah akar cukup banyak. Pada perlakuan dosis iradiasi 80 dan 100 Gy memiliki rata-rata jumlah akan sangat sedikit. Keadaan tersebut disebabkan banyaknya planlet anggrek yang mati serta terhambatnya 
pertumbuhan planlet akibat pemberian iradiasi gamma dengan dosis yang terlalu tinggi.

Menurut Wattimena (1990) proses pembentukan akar dimulai dari sel meristem yang secara terus-menerus membelah membentuk sekelompok sel-sel kecil (primordial akar) yang terus menerus berkembang. Apabila sel meristem selanjutnya terkena iradiasi dengan dosis yang terlalu tinggi maka akan terjadi kerusakan yang besar termasuk pada sel meristem dan selanjutnya pertumbuhan planlet akan terhambat dan planlet tidak akan mampu berkembang membentuk akar maupun daun. Keadaan ini teradi pada perlakuan dosis iradiasi 80 Gy dan 100 Gy, kerusakan yang diakibatkan oleh dosis ini sangat besar sehingga mengakibatkan banyaknya PLBs yang mati pada fase awal, dan PLBs yang masih dapat bertahan hidup selanjutnya tidak dapat berkembang dengan baik dan menghambat pertumbuhan daun serta akar pada planlet. Menurut Devy dan Sastra (2006) terjadinya penghambatan pertumbuhan akar pada tanaman jahe hasil iradiasi gamma disebabkan adanya gangguan aktivitas auksin endogen yang terjadi setelah proses iradiasi sehingga konsentrasi endogen berkurang dan akar pun tidak terbentuk.

\section{Lethal Dose (LD)}

Hasil analisis $L D_{30}$ dan $L D_{50}$ pada PLBs anggrek $D$. lasianthera yang sudah diiradiasi pada 6 taraf dosis iradiasi sinar gamma menghasilkan kurva Polynomial Fit dengan persamaan $\left(\mathrm{y}=97.769-1.918 \mathrm{x}+0.0321 \mathrm{x}^{2}-\right.$ $0.0002 \mathrm{x}^{3}$ ) dan didapatkan nilai $L D_{30}$ pada dosis iradiasi 19.7697 dan untuk $L D_{50}$ pada dosis iradiasi 67.3504 (Gambar 1). Hasil tersebut menunjukkan bahwa kemungkinan mutan terbanyak yang akan didapatkan berada diantara dosis iradiasi 19.7697 hingga 67.3504 karena pada rentang dosis tersebut kematian yang diakibatkan oleh proses iradiasi masih dibawah 50\%.

Penelitian yang dilakukan oleh Romeida et al. (2013) didapatkan bahwa mutan terbanyak yang dihasilkan pada proses iradiasi gamma pada PLBs anggrek Spathoglotis plicata Blume dihasilkan pada dosis sekitar $L D_{50}$. Nilai $L D_{50}$ yang didapatkan pada penelitian yang dilakukan oleh Romeida et al. (2013) berdasarkan persentase PLBs hidup adalah 47.71 dan nilai $L D_{30}$ yang didapatkan adalah
35.69. Nilai $L D_{50}$ pada PLBs anggrek Spathoglotis plicata Blume hasil iradiasi gamma ini memiliki nilai yang lebih kecil dibandingkan dengan nilai $L D_{50}$ yang didapatkan pada PLBs anggrek D. lasianthera pada penelitian ini. Pada penelitian lain yang dilakukan oleh Kurniati (2004) bahwa anggrek Phalaenopsis Hinamatsuri $x$ Doritaenopsis modern beauty hasil iradiasi gamma memiliki nilai $L D_{50}$ 27.8084. Perbedaan besarnya nilai $L D_{50}$ tersebut disebabkan karena perbedaan sensitifitas PLBs dalam menerima iradiasi gamma, pada penelitian yang dilakukan oleh Romeida et al. (2013) dan Kurniati (2014) memiliki tingkat sensitifitas yang lebih tinggi dibandingkan dengan $L D_{50}$ yang didapatkan dari hasil penelitian ini.

Sensitifitas tersebut dapat disebabkan perbedaan jenis PLBs atau perbedaan umur PLBs sehingga mengakibatkan berbedanya ketebalan dari dinding sel. Banyaknya PLBs yang diiradiasi dalam satu wadah juga dapat mengakibatkan perbedaan sensitifitas PLBs dalam menerima iradiasi. Semakin banyak dan menggerombolnya PLBs dalam satu wadah untuk iradiasi maka sensitifitasnya pun akan semakin menurun.

\section{Bentuk Daun dan Ukuran Akar}

Iradiasi sinar gamma dapat menyebabkan terjadinya perubahan di semua bagian tanaman termasuk daun dan akar, pada daun efek iradiasi sinar gamma dapat menyebabkan berubahnya ukuran dan bentuk daun. Pada perlakuan iradiasi yang diaplikasikan mengakibatkan beberapa daun berubah bentuk diantaranya adalah munculnya daun yang berbentuk melebar dan berbentuk keriting (Tabel 7).

Tabel 7. Morfologi daun anggrek $D$. lasianthera hasil iradiasi sinar gamma pada 22 MST (persentase)

\begin{tabular}{cccc}
\hline $\begin{array}{c}\text { Perlakuan } \\
(\mathrm{Gy})\end{array}$ & Memanjang & Melebar & Spiral \\
\hline 0 & $100(133 / 133)$ & 0 & 0 \\
20 & $98.4(125 / 127)$ & 0 & $1.6(2 / 127)$ \\
40 & $95.6(108 / 113)$ & $4.4(5 / 113)$ & 0 \\
60 & $80.7(88 / 109)$ & $18.4(20 / 109)$ & $0.9(1 / 109)$ \\
80 & $94.5(51 / 55)$ & $3.64(2 / 55)$ & $3.6(2 / 55)$ \\
100 & $83.3(25 / 30)$ & $16.7(5 / 30)$ & 0 \\
\hline
\end{tabular}


Gambar 1. Pengaruh dosis iradiasi terhadap persentase hidup PLBs anggrek $D$. Lasianthera dan $L D_{30}$ serta $L D_{50}$

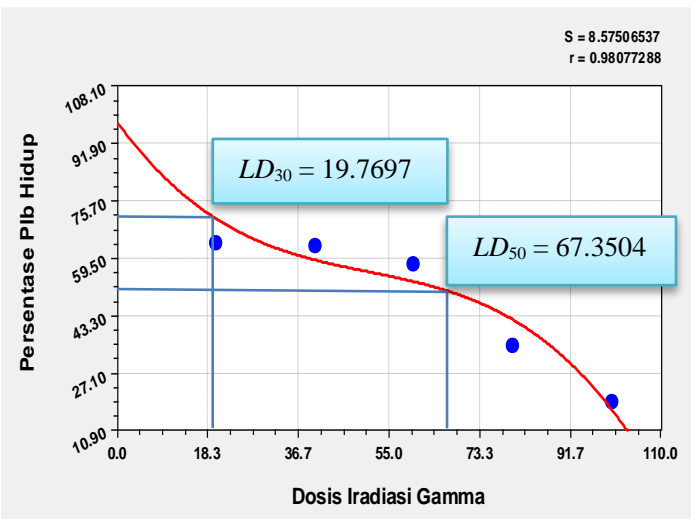

Bentuk daun normal pada planlet anggrek $D$. lasianthera adalah memanjang dengan ujung yang runcing. Data yang didapatkan menunjukkan bahwa bentuk memanjang masih sangat dominan dibandingkan dengan bentuk daun yang lain. Perubahan bentuk daun yang teramati terdapat hampir pada setiap perlakuan iradiasi dengan persentase yang tidak terlalu besar. Bentuk daun yang paling beragam ada pada perlakuan iradiasi 60 Gy dan 80 Gy. Pada perlakuan ini memiliki bentuk daun melebar dan spiral, sedangkan pada perlakuan dosis 20 Gy tidak muncul daun berbentuk melebar dan pada perlakuan dosis iradiasi 40 Gy dan 100 Gy tidak terdapat daun berbentuk spiral. Penelitian yang dilakukan oleh Royani et al. (2012) mendapatkan bentuk daun spiral pada tanaman obat sambiloto hasil iradiasi gamma cobalt 60. Pada penelitian lain yang dilakukan oleh Devy dan Sastra (2006), menghasilkan tunas roset serta daun kriting pada tanaman jahe hasil iradiasi gamma. Menurut Kurniati (2004) keragaman bentuk daun pada anggrek Phalaenopsis muncul sebagai akibat adanya abnormalitas sel mutan yang berkembang menjadi jaringan dan organ yang berbeda dari sel asalnya. Perlakuan dosis iradiasi gamma juga berpengaruh terhadap petumbuhan akar. Ukuran akar pada setiap dosis iradiasi menunjukkan adanya perbedaan yang terjadi karena dosis iradiasi gamma yang diaplikasikan menyebabkan terhambatnya pertumbuhan tanaman. Semakin tinggi dosis iradiasi yang diberikan, maka kerusakan yang dialami oleh tanaman akan lebih besar sehingga menghambat pertumbuhan tanaman termasuk pertumbuhan akar (Tabel 8).
Tabel 8. Morfologi akar planlet anggrek $D$. lasianthera hasil iradiasi sinar gamma pada 22 MST

\begin{tabular}{lccc}
\hline $\begin{array}{c}\text { Perlakuan } \\
\text { (Gy) }\end{array}$ & Besar & Sedang & Kecil \\
\hline 0 & $24.6(84 / 342)$ & $26.6(91 / 342)$ & $48.8(167 / 342)$ \\
20 & $18.7(53 / 294)$ & $28.9(85 / 294)$ & $53.1(156 / 294)$ \\
40 & $13.5(29 / 215)$ & $36.7(79 / 215)$ & $49.8(107 / 215)$ \\
60 & $13.5(26 / 193)$ & $34.2(66 / 193)$ & $52.3(101 / 193)$ \\
80 & 0 & $27.7(23 / 83)$ & $72.3(60 / 83)$ \\
100 & 0 & $23.5(20 / 85)$ & $76.5(65 / 85)$ \\
\hline
\end{tabular}

Akar berukuran kecil pada eksplan yang menerima perlakuan iradiasi lebih banyak dibandingkan dengan akar dengan ukuran sedang dan besar (Tabel 8). Pada penelitian ini akar berukuran besar sama sekali tidak terbentuk pada perlakuan dosis iradiasi $80 \mathrm{~Gy}$ dan $100 \mathrm{~Gy}$.

\section{KESIMPULAN}

Peningkatan iradiasi sinar gamma dari 20 Gy hingga 100 Gy nyata menekan persentase PLBs hidup, persentase PLBs berkecambah, jumlah daun, jumlah akar, dan persentase PLBs berakar serta ukuran akar pertumbuhan PLBs anggrek D. lasianthera. Semakin tinggi dosis iradiasi, maka semakin rendah kemampuan hidup dan pertumbuhan PLBs anggrek D. lasianthera. Lethal Dose $30 \%\left(L D_{30}\right)$ berada pada dosis iradiasi 19.76 dan untuk $L D_{50}$ berada pada dosis iradiasi 67.35. Perubahan bentuk daun yang teramati yakni munculnya daun berbentuk oval dan berbentuk spiral pada planlet hasil iradiasi.

\section{SARAN}

Penelitian lanjutan perlu dilakukan hingga fase generatif sehingga seluruh perubahan tanaman akibat proses iradiasi gamma dapat diidentifikasi dan selanjutnya dilakukan proses seleksi untuk mendapatkan perubahan yang diinginkan dan kemudian dapat digunakan sebagai varietas baru hasil mutasi. 


\section{DAFTAR PUSTAKA}

Alamendah. 2012. Anggrek Dendrobium lasianthera atau D. ostrinoglossum. http://alamendah.org/2012/07/12/anggrek -dendrobium-lasianthera-atau-dostrinog lossum/. [17 September 2013].

Aziz, S.A., D. Sukma, Nazi. 2014. Protocorm Like Bodies (PLBs) anggrek hasil silangan Phalaenopsis gigantea $\mathrm{x}$ Phalaenopsis violacea pada kombinasi media dan ZPT. J. Hort. Indonesia. 5(2): 118-127.

Devy, L., D.R. Sastra. 2006. Pengaruh radiasi sinar gamma terhadap kultur in vitro tanaman jahe. J. Sains dan Teknologi Indonesia. 8(1): 7-14.

Gonzales, M.A. 2007. Radiosensitivity of three species of ground orchid (Spatoglotis plicata, S. kimballiana var. angustifolia and $S$. tomentosa) to acute gamma radiation. Tesis. Central Luzon State University. Philippines.

Harmita, M. Radji. 2008. Buku Ajar Analisis Hayati Edisi 3. Buku kedokteran ECG. Jakarta.

Kurniati, R. 2004. Induksi keragaman genetik Phalaenopsis hinamatsuri x Doritaenopsis modern beauty dan Phalaenopsis amabilis x Phalaenopsis tapei gold 'GS' dengan menggunakan iradiasi sinar gamma. Tesis. Institut Pertanian Bogor. Bogor.

Lamadji, S., L. Hakim, Rustidja. 1999. Akselarasi pertanian tangguh melalui pemuliaan non-konvensional. Prosiding Simposium V Pemuliaan Tanaman PERIPI Komda Jawa Timur, Indonesia. hal. 28-32. Jawa Timur.

Poespodarsono, S. 1988. Dasar-dasar Ilmu Pemuliaan Tanaman. Pusat Antar Universitas (PAU) IPB. Bogor.
Romeida, A., S.H. Sutjahjo, A. Purwito, D. Sukma, Rustikawati. 2013. Induksi mutasi protocorm like bodies (PLBs) anggrek Spathoglottis plicata Blume. Aksesi Bengkulu pada sebelas taraf dosis iradiasi sinar gamma. Prosiding Simposium dan Seminar Bersama PERAGIPERHORTI- PERIPI-HIGI. hal. 381387.

Royani, J.I., A. Purwito, W. Sumaryono. 2012. Pengaruh irradiasi sinar gamma cobalt 60 terhadap karakter morfologi tanaman obat sambiloto (Andrographis paniculata (Burm.f.) Wallich Ex Ness). Prosiding Seminar Nasional POKJANAS TOI XLII. hal. 63-76.

Sabran, M., A. Krismawati, Y.R. Galingging, M.A. Firmansyah. 2003. Eksplorasi dan karakterisasi tanaman anggrek di Kalimantan Tengah. Bul. Plasma Nutfah. 9(1): 1-6.

Siska, D.M., I. Mahadi, Zulfarina. 2013. Pengaruh pemberian hormon IAA dan BAP terhadap pertumbuhan tunas anggrek Dendrobium Phalaenopsis Fitzg secara in vitro. FKIP. Universitas Negeri Riau (UNRI). Riau.

Smart. 2008. Dendrobium lasianthera. http:// www.orchidsonline.com.au/node/2729. [20 september 2013].

Soedjono, S. 2003. Aplikasi mutasi induksi dan variasi somaklonal dalam pemuliaan tanaman. J. Litbang Pertanian. 22(2): 70-78.

Soedjono, S., N. Solvia, Suskandari. 1996. Tanggapan pertumbuhan anggrek Dendrobium terhadap dosis radiasi sinar gamma. J. Aplikasi Isotop dan Radiasi. hal. 83-88.

Suranto, H. 2003. Peran iptek nuklir dalam pemuliaan tanaman untuk mendukung industri pertanian. Prosiding Pertemuan dan Presentasi Ilmiah Penelitian Dasar Ilmu Pengetahuan dan Teknlogi Nuklir. P3TM-BATAN. hal. 308-316. Yogyakarta. 
Wattimena, G.A. 1990. Penggunaan ZPT pada perbanyakan propagula tanaman. Seminar Nasional Agrokimia UNPAD. hal. 1-3.

Widiastoety, D., P. Warpodo, S. Nina. 2000. Pengaruh naungan terhadap produksi tiga kultivar bunga anggrek Dendrobium. Balithi. Jakarta.
Widiastoety, D. 2009. Pengaruh tiamin terhadap pertumbuhan planlet anggrek Oncidium secara in vitro. J. Hort. 19: 35-36.

Widiastoety, D, N. Solvia, M. Soedarjo. 2010. Potensi anggrek Dendrobium dalam meningkatkan variasi dan kualitas anggrek bunga potong. J. Litbang Pertanian. 29(3): 101-106. 